\title{
Correction: The atypical ubiquitin ligase RNF31 stabilizes estrogen receptor $a$ and modulates estrogen-stimulated breast cancer cell proliferation
}

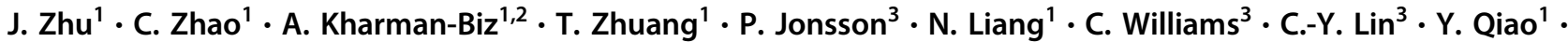 \\ K. Zendehdel ${ }^{2} \cdot$ S. Strömblad ${ }^{1} \cdot$ E. Treuter ${ }^{1} \cdot$ K. Dahlman-Wright ${ }^{1}$
}

Published online: 27 September 2018

(c) Springer Nature Limited 2018

Correction to: Oncogene; https://doi.org/10.1038/onc.2013. 573; published online 20 January 2014.

Since the publication of the above article, the authors have noted that the input data in Fig. $6 \mathrm{E}$ is incorrect. The correct data are included in the below Fig. 6E. The mistake does not affect the conclusions of the paper as the levels of input proteins remain similar between samples. We apologise for any inconvenience caused by this error.

K. Dahlman-Wright

karin.dahlman-wright@ki.se

1 Department of Biosciences and Nutrition, Karolinska Institutet, Huddinge, Sweden

2 Cancer Research Center, Cancer institute of Iran, Tehran University of Medical Sciences, Tehran, Iran

3 Center for Nuclear Receptors and Cell Signaling, Department of Biology and Biochemistry, University of Houston, Houston, TX, USA 


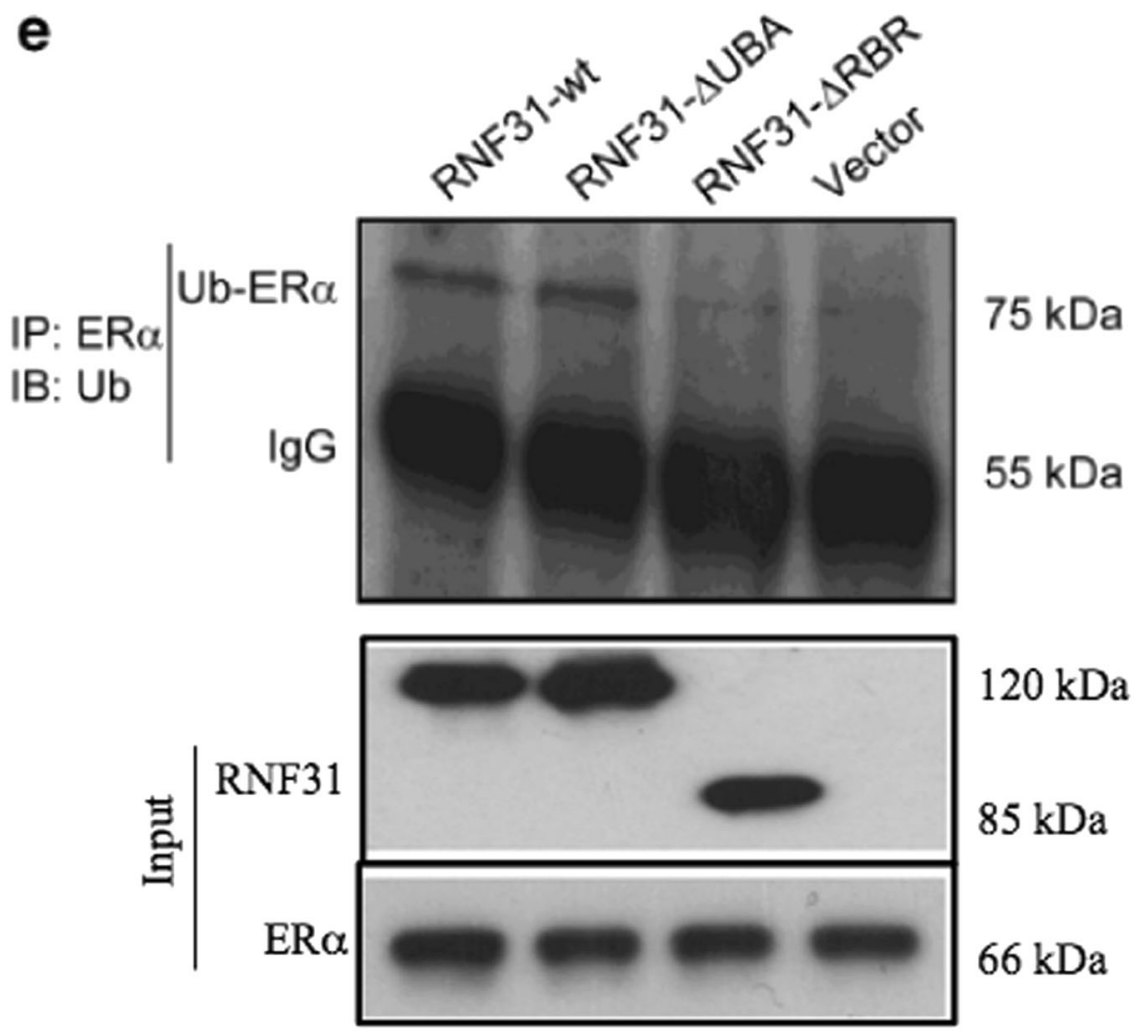

Fig. 6 RNF31 triggers ER $\alpha$ mono-ubiquitination. a Detection of a potentially mono-ubiquitinated form of ER $\alpha$ upon RNF31 overexpression. HEK-293 cells were transfected with ER $\alpha$ together with plasmids expressing Myc-tagged RNF31 or the Myc-tag alone. Forty-eight hours after transfection, whole-cell extracts were prepared and levels of ER $\alpha$ protein assayed by western blot analysis. The predicted molecular weights of RNF31, ER $\alpha$, mono-ubiquitinated ER $\alpha$ and of the internal control GAPDH are indicated. b Detection of endogenous mono-ubiquitinated ER $\alpha$ upon RNF31 depletion. MCF-7 cells were transfected with siRNF31 or siControl. Forty-eight hours after transfection, whole-cell extracts were prepared and levels of ER $\alpha$ protein assayed by western blot analysis. The predicted molecular weights of RNF31, ER $\alpha$, mono-ubiquitinated ER $\alpha$ and the internal control GAPDH are indicated. $\mathbf{c}$ Deletion of the RNF31 RBR domain abolishes the potentially mono-ubiquitinated form of ER $\alpha$. HEK-293 cells were transfected with ER $\alpha$ together with plasmids expressing Myc-tagged full-length RNF31 derivatives or the Myc-tag alone. Forty-eight hours post transfection, cell extracts were prepared and ER $\alpha$ forms were detected by western blot analysis. The predicted molecular weights of RNF31, ER $\alpha$, mono-ubiquitinated ER $\alpha$ and of the internal control GAPDH are indicated. d Direct evidence for ER $\alpha$ monoubiquitination. Immunoprecipitation of ubiquitinated proteins from MCF-7 cell extracts upon overexpression of RNF31. Ubiquitinated ER $\alpha$ species were detected by western blots using anti-ER $\alpha$, identifying a prominent $75 \mathrm{kDa}$ mono-ubiquitinated ER form. e ER $\alpha$ mono-ubiquitination requires the RNF31 RBR domain. Plasmids expressing Myc-tagged RNF31 derivatives were transfected into HEK-293 cells together with the ER $\alpha$ expression plasmid. Whole-cell extracts were subjected to immunoprecipitation of ER $\alpha$ and subsequently analyzed for ubiquitinated ER $\alpha$ forms by western blot analysis using anti-ubiquitin. The predicted molecular weight of mono-ubiquitinated ER $\alpha$ is indicated 